\title{
Development of a new sternal dehiscence prediction scale for decision making in sternal closure techniques after cardiac surgery
}

Ehab Nooh', Colin Griesbach², Johannes Rösch', Michael Weyand ${ }^{1}$ and Frank Harig ${ }^{1 *}$ (D)

\begin{abstract}
Background: After sternotomy, the spectrum for sternal osteosynthesis comprises standard wiring and more complex techniques, like titanium plating. The aim of this study is to develop a predictive risk score that evaluates the risk of sternum instability individually. The surgeon may then choose an appropriate sternal osteosynthesis technique that is risk- adjusted as well as cost-effective.

Methods: Data from 7.173 patients operated via sternotomy for all cardiovascular indications from 2008 until 2017 were retrospectively analyzed. Sternal dehiscence occurred in $2.5 \%$ of patients $(n=176)$. A multivariable analysis model examined pre- and intraoperative factors. A multivariable logistic regression model and a backward elimination based on the Akaike Information Criterion (AIC) a logistic model were selected.

Results: The model showed good sensitivity and specificity (area under the receiver-operating characteristic curve, AUC: 0.76$)$ and several predictors of sternal instability could be evaluated. Multivariable logistic regression showed the highest Odds Ratios (OR) for reexploration (OR 6.6, confidence interval, Cl [4.5-9.5], $p<0.001$ ), obesity (body mass index, $\left.\mathrm{BMI}>35 \mathrm{~kg} / \mathrm{m}^{2}\right)$ (OR 4.23, [Cl 2.4-7.3], $p<0.001$ ), insulin-dependent diabetes mellitus (IDDM) (OR 2.2, Cl $[1.5-3.2], p=0.01$ ), smoking (OR 2.03, [Cl 1.3-3.08], $p=0.001$ ). After weighting the probability of sternum dehiscence with each factor, a risk score model was proposed scaling from -1 to 5 points. This resulted in a risk score ranging up to 18 points, with an estimated risk for sternum complication up to $74 \%$.
\end{abstract}

Conclusions: A weighted scoring system based on individual risk factors was specifically created to predict sternal dehiscence. High-scoring patients should receive additive closure techniques.

Keywords: Cardiac surgery, Sternal dehiscence, Prediction, Scoring system, Tailored technique

\footnotetext{
* Correspondence: frank.harig@uk-erlangen.de

'Department of Cardiac Surgery, University Hospital Erlangen, FriedrichAlexander University Erlangen- Nuremberg, Krankenhausstr. 12, D-91054 Erlangen, Germany

Full list of author information is available at the end of the article
}

(c) The Author(s). 2021 Open Access This article is licensed under a Creative Commons Attribution 4.0 International License, which permits use, sharing, adaptation, distribution and reproduction in any medium or format, as long as you give appropriate credit to the original author(s) and the source, provide a link to the Creative Commons licence, and indicate if changes were made. The images or other third party material in this article are included in the article's Creative Commons licence, unless indicated otherwise in a credit line to the material. If material is not included in the article's Creative Commons licence and your intended use is not permitted by statutory regulation or exceeds the permitted use, you will need to obtain permission directly from the copyright holder. To view a copy of this licence, visit http://creativecommons.org/licenses/by/4.0/ The Creative Commons Public Domain Dedication waiver (http://creativecommons.org/publicdomain/zero/1.0/) applies to the data made available in this article, unless otherwise stated in a credit line to the data. 


\section{Background}

After the first description of the median sternotomy as an operative access to the mediastinum by MILTON in 1897, this is still the most common approach in cardiovascular surgery [1]. The evolution in modern cardiac surgery creates less and minimal invasive surgical approaches to the heart, but this approach is relatively safe and offers the best exposure in most of the cardiac surgical procedures [2]. As every surgical procedure bears the potential of complications, this approach also bears a potential risk of sternal dehiscence and infection that may threaten the outcome of the operation and potentially affect not only the patient's physical but also his psychological recovery. It is also a matter of economics, as complicated postoperative courses are up to 2.8 times more expensive than uncomplicated cases $[3,4]$.

The incidence of surgical site infections was targeted in many studies trying to evaluate the risk factors [3-10] and an incidence of $3.5 \%$ for major infections was found [3]. Even risk score models were created [6-9], but they were mostly designed not for all indications but only for coronary patients and especially associated with the usage of bilateral internal thoracic arteries (BITA) in coronary artery bypass grafting (CABG) [10].

The complication of sternal instability alone is focused only in some studies and reported to occur in 3\% (0.5$8.0 \%)$ of patients after sternotomy $[11,12]$. In order to prevent those complications, pre-emptive risk-reducing surgical techniques like sternal rigid plate fixation have been evolved [13], and superior effects over simple wiring technique concerning bone healing, postoperative pain and overall costs could be shown in a multicentre randomized controlled trial (RCT) [4].

However, a general use of more expensive techniques is not always technically required nor economically justified. The standard sternal wires technique, which is applicable in the vast majority of cases, is fast and costeffective. Nowadays, the increased morbidity of cardiac patients made the use of wires not as effective as before. Alternative techniques to overcome this surgical challenge comprise special wire techniques (e.g. Robicsek's figure of eight, [11]), the usage of metallic bands (Parham bands [14]) and finally the technique of rigid plates fixation using titanium plates and screws [4]. These closure techniques are definitely more effective but on the other hand time-consuming and expensive [13]. The identification of patients who are at high risk for sternal instability and consequently adopting the suitable surgical technique is the real surgical challenge. Therefore, it is necessary to develop a risk model to predict the risk of sternal dehiscence.

In the present study, the authors have reviewed retrospectively their surgical experience over the last 10 years with sternal complications after all-type cardiothoracic operations. The aim of the study was to develop a risk model to predict sternal dehiscence in surgical patients who may receive special intervention strategies to reduce rates of sternal instability.

\section{Methods \\ Study population}

From 1 January 2008 throughout 2017, 8.615 adult consecutive patients with all-type heart disease underwent cardiac surgery through median sternotomy at the authors' institution, a quaternary, acute care university hospital in northern Bavaria. Most of the patients (61\%) underwent CABG, 29\% underwent valve surgery and 10\% aortic surgery. Preoperative antibiotic prophylaxis was part of every patient's standardized medical treatment.

After checking for inclusion (age over 18 years, surgery through median sternotomy) and exclusion criteria (lateral thoracotomy, complex sternal closure techniques), the data of a cohort of 7.173 patients were analysed (Table 1).

\section{Human participant protection}

This retrospective study complied with the Helsinki Declaration (2000) and approval to perform this analysis was given by the local Ethics Committee (EC, No.233_20 $\mathrm{BC}$ ), based on retrospective data retrieval. For this reason, the EC waived the need for written patients' informed consent.

\section{Data collection and follow-up}

Within the cohort of 7173 patients, a subset of 176 (2.5\%) developed a sternal dehiscence, regardless of a primary 'aseptic' dehiscence or secondary to an infection (septic dehiscence). We have deliberately omitted the post-operative risk factors, as they could not alter the decision of the sternal closure technique.

\section{Definitions and outcome measures}

The definition of sternal dehiscence is a clinically noticeable mobility of the sternal parts that causes pain or abnormal respiratory movement and leads to a surgical intervention.

\section{Statistical analysis}

For the variables listed, a multivariable logistic regression model was estimated and within this model, the variable "complication Yes vs. No", was the dichotomous outcome. Subsequently, a backward elimination based on the Akaike Information Criterion (AIC) was used to select a logistic model best suitable for prediction. Odds ratios were calculated for each variable and the area under the curve (AUC) was determined with corresponding 95\% confidence interval. The analysis was performed with the software $\mathrm{R}$ version 3.6.3 [15] by 
Table 1 Preoperative patients' characteristics ${ }^{a}$

\begin{tabular}{|c|c|c|c|}
\hline Characteristics & $\mathrm{n}$ & $\%$ & Range \\
\hline & 7173 & & \\
\hline \multicolumn{4}{|l|}{ Age (years) } \\
\hline Mean & 66.5 & $( \pm 12.4)$ & $(22-85)$ \\
\hline$<60$ & 1878 & 26.2 & \\
\hline$>60$ & 5295 & 73.8 & \\
\hline \multicolumn{4}{|l|}{ Gender } \\
\hline Male & 5306 & 74.0 & \\
\hline Female & 1867 & 26.0 & \\
\hline \multicolumn{4}{|l|}{ BMI $\left(\mathrm{kg} / \mathrm{m}^{2}\right)$} \\
\hline Mean & 28,1 & $( \pm 4.6)$ & $(14-57)$ \\
\hline$<25$ & 1861 & 25.9 & \\
\hline $25-35$ & 4791 & 66.8 & \\
\hline$>35$ & 521 & 7.3 & \\
\hline \multicolumn{4}{|l|}{ Diabetes mellitus } \\
\hline No & 4978 & 69.4 & \\
\hline NIDDM & 1356 & 18.9 & \\
\hline IDDM & 839 & 11.7 & \\
\hline \multicolumn{4}{|l|}{$\mathrm{COPD}^{\mathrm{b}}$} \\
\hline Yes & 624 & 8.7 & \\
\hline No & 6549 & 91.3 & \\
\hline Renal impairment $^{c}$ & 190 & 2.6 & \\
\hline \multicolumn{4}{|l|}{ Smoker } \\
\hline No & 3854 & 53.7 & \\
\hline Former & 2034 & 28.4 & \\
\hline Current $^{d}$ & 1285 & 17.9 & \\
\hline \multicolumn{4}{|l|}{ Previous cardiac OP } \\
\hline no & 6096 & 85.0 & \\
\hline$>6$ months & 1077 & 15.0 & \\
\hline \multicolumn{4}{|l|}{ Cardiogenic shock } \\
\hline No & 6891 & 96.1 & \\
\hline$<3$ weeks & 82 & 1.1 & \\
\hline$<48 \mathrm{~h}$ & 200 & 2.8 & \\
\hline \multicolumn{4}{|l|}{ Surgical priority } \\
\hline Elective & 3197 & 44.6 & \\
\hline Urgent & 3111 & 43.4 & \\
\hline Emergency & 865 & 12.1 & \\
\hline \multicolumn{4}{|l|}{ OP-Duration (min) } \\
\hline Mean (SD) & 214 & $( \pm 83.5)$ & $(17-1135)$ \\
\hline$<300$ & 6436 & 89.7 & \\
\hline$>300$ & 737 & 10.3 & \\
\hline \multicolumn{4}{|l|}{ Re-Exploration } \\
\hline Yes & 420 & 5.9 & \\
\hline No & 6753 & 94.1 & \\
\hline
\end{tabular}

Legend: $B M I$ Body mass index, COPD Chronic obstructive pulmonary disease ${ }^{a}$ Values are no. of patients or mean $+\mathrm{SD}$ with interquartile range in brackets

b,call stages, Definition: see EuroSCORE II; ${ }^{d}$ within last 2 months preoperativel 
colleagues of the IMBE, Institute of Medical informatics, Biometry and Epidemiology of the Friedrich-AlexanderUniversity Erlangen-Nürnberg (C.G., co-author and E.W., see acknowledgement). For the selection of the best model, the functions $\operatorname{glm}()$ and $\operatorname{step}()$ of the "stats" package were used, whereas the function $\operatorname{roc}()$ of the package "pROC" was used to compute the AUC.

Exclusion criterion was the primary use of any other complex techniques for sternal osteosynthesis.

\section{Results}

Risk factors for sternal dehiscence (malunion of the sternum) and uni-variable analysis

The data of 7173 patients were analysed and 176 (2.5\%) patients were found to suffer from sternal dehiscence due to malunion of the sternum (MUST). These patients were compared to 6997 (97.5\%) patients who did not develop a sternal complication.

The following factors were risk factors for MUST according to the univariable analysis (Table 2)

Older age (age $>60 \mathrm{y})$, male gender, severe obesity (BMI $\geq 35 \mathrm{~kg} / \mathrm{m}^{2}$ ), insulin-dependent diabetes mellitus (IDDM), current smoking (inhalative tobacco use within 2 months preoperatively), previous cardiac operation and rethoracotomy for re-exploration of the mediastinum.

\section{Risk factors for sternal dehiscence (malunion of the sternum) and multi-variable analysis}

Using these dependent risk factors for MUST, a multi-variable analysis model was developed to examine preoperative risk factors. The following were risk factors for MUST according to the multi-variable analysis (Table 3)

Re-exploration of the mediastinum (e.g. for bleeding), severe obesity (BMI $\geq 35 \mathrm{~kg} / \mathrm{m}^{2}$ ), IDDM, current smoking (inhalative tobacco use within 2 months preoperatively), older age (age $>60 \mathrm{y}$ ), moderate obesity (BMI $\geq 25$ and $<$ $35 \mathrm{~kg} / \mathrm{m}^{2}$ ), male gender, previous cardiac operation and former smoking (<2 months before OP), COPD.

\section{The new predictive scoring system for malunion of the sternum after cardiac surgery}

We created a model of a new scoring system (MUSTScore) to predict mal-union of the sternum after sternotomy for cardiac surgery according to the multivariable analysis model. After performing backward selection on the full model (Table 3), the remaining factors coefficient estimates were scaled to the largest one being 5 and rounded to the nearest whole (Tables 4 and 5). This resulted in a risk score between -1 and 18 , reflecting an estimated risk for sternum complication of 0.22 to $73.65 \%$, while the average risk is $2.5 \%$.

\section{The accuracy of prediction}

The accuracy of prediction was assessed with the receiver-operating characteristic curve (ROC) and the calculation of the area under the receiver-operating characteristic curve (AUC) (Fig. 1).

In this model, the AUC was calculated 0.76 [95\% CI: $0.72 ; 0.80]$. The scoring system based on this model showed an AUC of 0.75 [95\% CI: 0.72; 0.79].

According to arbitrary definitions of Sweats [16], the accuracy of prediction can be defined as moderate (AUC: 0.7-0.9).

\section{Discussion}

Sternal dehiscence after sternotomy for cardiac operations severely affect the patients' physical and psychological recovery. It is also a matter of economics, as complicated postoperative courses are up to 2.8 times more costly than uncomplicated cases. The complication of sternal instability alone is discussed only in some studies and reported to occur in 3\% (0.5-8.0\%) of patients after sternotomy [11, 12]. Preventive strategies comprise the usage of vacuum-assisted wound closure therapy, special surgical techniques to reinforce the osteosynthesis and the development of models to identify patients at high risk for sternal wound complications.

Several models focus on special surgical settings like the usage of bilateral internal thoracic artery grafting in coronary artery bypass grafting [10]. Moreover, some models were created to prevent infections on multiple surgical sites (sternum, legs) [3, 5], the development of infections alone $[3,5,6]$ or in combination with sternal instability [13]. Although sternal wound complications have a complex pathogenesis depending on specific comorbidities as well as pre-, intra- and postoperative factors, we consider the sternal instability as the initial step towards further sternal wound healing complications including deep sternal wound infections and mediastinitis. In this context, the development of a model to predict the risk of sternal dehiscence may be useful to calculate patients' risk rationally and individually and to target these patients in the operating room for special surgical intervention strategies.

The aim of this study was both to analyse the risk factors for sternal instability and develop a predictive risk score based on the results of this analysis. Surgeons who operate their patients via sternotomy would be able to evaluate the risk of sternum instability individually, and may optimize the sternal osteosynthesis technique. Up to now, there is no scoring system specifically created to predict the individual risk for sternal instability due to mal-union of the sternum (MUST).

Among all patients $(n=8.615)$ who underwent all-type cardiothoracic operations in a quaternary university 
Table 2 Risk factors (univariable analysis) ${ }^{a}(n=7173)$

\begin{tabular}{lll}
\hline Variable & \multicolumn{2}{l}{ Sternal dehiscence } \\
\cline { 2 - 3 } $\mathbf{n}$ & $\%$ \\
\hline $\mathbf{1 7 6}$ & 2.5
\end{tabular}

\begin{tabular}{ll}
\hline No sternal complication & \\
\hline $\mathbf{n}$ & $\%$ \\
\hline 6997 & 97.5
\end{tabular}

$P$-value

Age (years)

Mean

$<60$

$>60$

Gender

$\begin{array}{ll}\text { Male } & 142 \\ \text { Female } & 34\end{array}$

BMI $\left(\mathrm{kg} / \mathrm{m}^{2}\right)$

Mean

$<25$

25-35

$>35$

Diabetes mellitus

$\begin{array}{ll}\text { No } & 94 \\ \text { NIDDM } & 40 \\ \text { IDDM } & 42\end{array}$

COPD

Yes

No

Renal failure ${ }^{\mathrm{e}}$

Yes

No

Smoker

$\begin{array}{ll}\text { No } & 73 \\ \text { Ex- } & 61 \\ \text { Current } & 42\end{array}$

Previous cardiac OP

No

$>6$ months

7

169

4

96

42

35

23

42

ardiogenic shock

No

$<3$ weeks

$<48 \mathrm{~h}$.

154

22

Surgical priority

Elective

Urgent

Emergency

OP-Duration

Mean (SD)

$<300$ min

$>300 \mathrm{~min}$

171

2

3

Re-Exploration

16

16

1.1

1.7

39

236

148

28
66.9

34

142

142

34

\section{9}

147
(22-85)

19

81

81

19

(17-46)

15.4

65.3

19.3

66.5

1819

5178

5178

1819

28.1

1816

4691

490

4884

1316

797

595

6402

183

6814

3779

1976

1242

5943

1054

6730

80

187

3128

3032

837

$+130$

45
84

6288

709
(18-92)

26

74

0.0065

0.0247

26

(14-57)

26.0

67.0

7.0

$<0.0001$

69.8

18.8

11.4

$0.1408^{b}$

$<0.0001^{\mathrm{C}}$

8.5

0.0507

91.5

2.6

0.0543

97.4

54.0

28.2

17.7

0.0546

0.0009

84.9

15.1

0.0533 $0.6494^{\mathrm{h}}$

43.3

12.0

$0.1169^{i}$

96.2

1.1

2.7

$0.7441^{f}$

$0.1124^{\mathrm{g}}$

447

3.3
12.0

89.9

10.1

0.1626 
Table 2 Risk factors (univariable analysis) ${ }^{a}(n=7173)$ (Continued)

\begin{tabular}{|c|c|c|c|c|c|}
\hline \multirow[t]{2}{*}{ Variable } & \multicolumn{2}{|c|}{ Sternal dehiscence } & \multicolumn{2}{|c|}{ No sternal complication } & \multirow[t]{2}{*}{$P$-value } \\
\hline & $\mathrm{n}$ & $\%$ & $n$ & $\%$ & \\
\hline Yes & 47 & 27 & 373 & 5.3 & $<0.0001$ \\
\hline No & 129 & 73 & 6624 & 94.7 & \\
\hline
\end{tabular}

Legend: The incidence of each variable is shown in the group with sternal dehiscence and with no sternal complication. Univariable analysis was performed and $P$-value was calculated

${ }^{a}$ Values are no. of patients or mean + SD with interquartile range in brackets; BMI Body Mass Index, NIDDM Non Insulin Dependent Diabetes mellitus, IDDM Insulin dependent Diabetes mellitus; ${ }^{b} \mathrm{NIDD} \bar{M}$ vs. no DM; ' IDDM vs. no DM; COPD: Chronic obstructive pulmonary disease; ${ }^{\mathrm{d}, \mathrm{e}}$ all stages, as defined by EuroScore II;

${ }^{\mathrm{f} C}$ Cardiogenic shock within 3 weeks vs. no; ${ }^{9}$ Cardiogenic shock $>48 \mathrm{~h}$ vs. no; ' ${ }^{2}$ elective vs. urgent; 'elective vs. emergency

hospital setting over a 10-years period from 2008 to 2017 mal-union of the sternum (MUST) occurred in $2.5 \%$ of the patients $(n=176)$.

Other authors reported a higher sternal complication rate for wire cerclage usage compared to rigid plate fixation of the sternum (5\% vs. $0 \%$ after 6 months) [4]. Although rigid plate fixation was associated with a trend toward greater index hospitalization costs, 6-month follow-up costs tended to be lower. As a result, total costs were similar between groups.

Ramann et al. [13] investigated the sternal bone healing in a multicentre RCT and compared pain scores and narcotic usage in patients who received rigid plate fixation versus conventional wire cerclage. He could find a sternal union rate of $70 \%$ at 6 months in patients with rigid plate fixation compared to $24 \%$ in patients with

Table 3 Risk factors for sternal instability (multivariate analysis) $(n=7173)$

\begin{tabular}{|c|c|c|c|}
\hline \multirow[t]{2}{*}{ Factor } & \multicolumn{3}{|c|}{ Preoperative evaluation } \\
\hline & $\overline{O R}$ & $(95 \% \mathrm{Cl})$ & $P$-value \\
\hline Re-exploration & 6.61 & $(4.51-9.54)$ & $<0.001$ \\
\hline $\mathrm{BMl} \geq 35 \mathrm{~kg} / \mathrm{m}^{2}$ & 4.23 & $(2.46-7.34)$ & $<0.001$ \\
\hline IDDM & 2.24 & $(1.50-3.29)$ & 0.010 \\
\hline Smoker (within 2 months preop.) & 2.03 & $(1.32-3.08)$ & 0.001 \\
\hline Age $>60$ y & 1.77 & $(1.19-2.72)$ & 0.007 \\
\hline $\mathrm{BMI} \geq 25-35 \mathrm{~kg} / \mathrm{m}^{2}$ & 1.66 & $(1.09-2.62)$ & 0.022 \\
\hline Male gender & 1.56 & $(1.00-2.37)$ & 0.030 \\
\hline Previous cardiac OP & 0.60 & $(0.36-0.95)$ & 0.037 \\
\hline Smoker (former) & 1.44 & $(1.44-2.08)$ & 0.051 \\
\hline COPD & 1.53 & $(0.97-2.33)$ & 0.059 \\
\hline Cardiogenic shock (< 48 h preop.) & 0.38 & $(0.09-1.07)$ & 0.112 \\
\hline Priority: emergency & 1.48 & $(0.89-2.39)$ & 0.117 \\
\hline NIDDM & 1.36 & $(0.91-1.99)$ & 0.126 \\
\hline OP Duration $>5 \mathrm{~h}$ & 1.38 & $(0.86-2.15)$ & 0.163 \\
\hline Renal impairment (all stages) & 1.42 & $(0.58-2.98)$ & 0.398 \\
\hline Priority: urgent & 1.08 & $(0.77-1.51)$ & 0.649 \\
\hline Cardiogenic shock (<3 weeks preop.) & 0.79 & $(0.13-2.63)$ & 0.740 \\
\hline
\end{tabular}

OR Odds ratio, $\mathrm{Cl}$ Confidence intervall, $B M I$ Body mass index, IDDM Insulindependent diabetes mellitus, COPED Chronic obstructive pulmonary disease, NIDDM Non-insulin-dependent diabetes mellitus sternal wiring. Pain scores and narcotic usages were significantly lower in the plate fixation group.

\section{Predictive scoring systems or computed scales for the occurrence of surgical complications}

Those predictive scales are instruments to optimize patients' outcome. Patients at a high risk for a complicated course may need more attention than patients at standard risk.

In 1992, O'Connor et al. [7] developed a multivariate clinical prediction rule using logistic regression analysis, a statistical method that allows the calculation of the conditional probability of death (in-hospital mortality associated with CABG surgery). The area under the ROC curve obtained from the training set of data was 0.74 (perfect, 1.0). The prediction rule performed well when used on a test set of data (area, 0.76). The correlation between observed and expected numbers of death was 0.99 .

\section{Prediction of major infections after cardiac surgery}

Other studies focused on major all- site infections after cardiac surgery. As published in 2005, Fowler et al. [3] analysed 331.429 patients (operated 2002-2003 for

Table 4 The scoring of the risk factors for MUST

\begin{tabular}{ll}
\hline Risk factor & Points \\
\hline Re-exploration & 5 \\
$\mathrm{BMI}>35 \mathrm{~kg} / \mathrm{m}^{2}$ & 4 \\
Age $>60$ years & 2 \\
IDDM & 2 \\
Smoker: current & 2 \\
Male gender & 1 \\
COPD & 1 \\
OP Duration $>300$ min & 1 \\
BMI 25-35 kg/m ${ }^{2}$ & 1 \\
NIDDM & 1 \\
Smoker: former & 1 \\
Previous cardiac OP $>6$ months & -1 \\
\hline
\end{tabular}

MUST Mal-Union of the Sternum, BMI Body Mass Index, IDDM Insulin dependent diabetes mellitus, COPD Chronic obstructive, Pulmonary disease, NIDDM Non-insulin dependent diabetes mellitus 
Table 5 The total score and expected risk of MUST

\begin{tabular}{|c|c|}
\hline Total score & Expected risk of MUST (\%) \\
\hline-1 & 0.2 \\
\hline 0 & 0.3 \\
\hline 1 & 0.5 \\
\hline 2 & 0.7 \\
\hline 3 & 1.0 \\
\hline 4 & 1.4 \\
\hline 5 & 2.1 \\
\hline 6 & 3.0 \\
\hline 7 & 4.3 \\
\hline 8 & 6.1 \\
\hline 9 & 8.7 \\
\hline 10 & 12.2 \\
\hline 11 & 16.8 \\
\hline 12 & 22.7 \\
\hline 13 & 29.9 \\
\hline 14 & 38.3 \\
\hline 15 & 47.5 \\
\hline 16 & 56.9 \\
\hline 17 & 65.8 \\
\hline 18 & 73.7 \\
\hline
\end{tabular}

MUST Mal-Union of the STernum
CABG) from the STS National Cardiac Database to identify risk factors for major infection. A simplified risk scoring system of twelve variables accurately predicted risk for major infection (overall, 3.5\%; of them, 25\% mediastinitis, 33\% saphenous harvest site infection, 35\% septicaemia, $7 \%$ multiple sites). Patients with a major infection had a significantly higher mortality than patients without an infection (17.3\% versus 3.0\%).

Hussey et al. [5] performed a more specific analysis of sternal wound infections after cardiac surgery in 1998. In this study, a sternal wound infection prediction scale (SWIPS) was developed and further revised (SWIPS-R). A multivariate logistic regression with 12 risk factors provided up to $76 \%$ correct predictions.

The scoring systems were mainly considered for sternal wound infections generally after any cardiac operation $[3,5]$ or more specially like CABG surgery with one or bilateral use of the BITA, analysed by Gatti et al. [10]. With this special scoring system inaugurated by Gatti, deep sternal wound infection (DSWI) after BITA grafting, can be predicted with a accuracy of 0.72 to 0.73 (AUC of the ROC-curve).

Until now, the most effective prevention methods including scoring systems have not been found. They remain objects of an ongoing discussion.

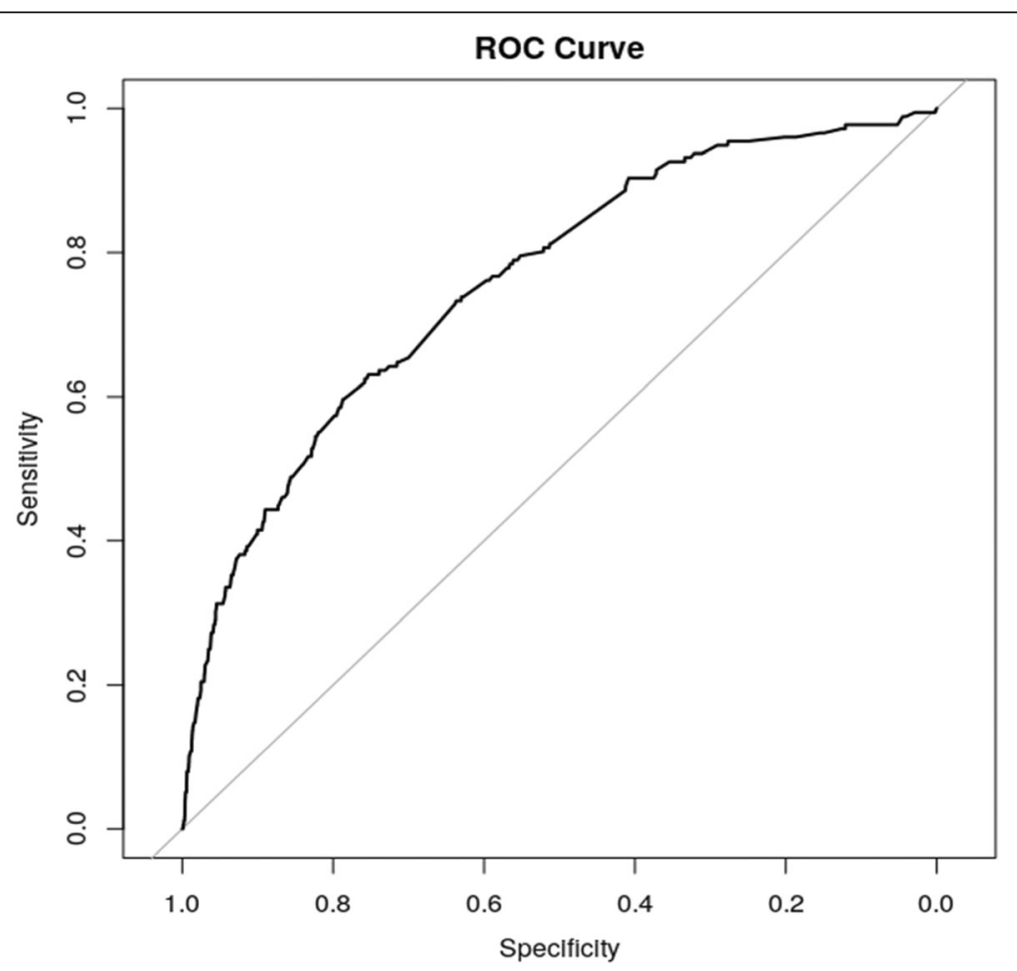

Fig. 1 The predictive scoring system for MUST after sternotomy for cardiac surgery. Legend: The accuracy of prediction of the model was assessed with the receiver-operating characteristic curve (ROC) and the calculation of the area under the receiver-operating characteristic curve (AUC). The AUC was calculated 0.76 [95\% Cl: 0.72; 0.80]. AUC: Area under the curve. ROC Curve: Receiver Operating Characteristic curve. MUST: Mal-Union of the Sternum 
In a review of 2002, Losanoff, Richmann and Jones [17], described not only preoperatively known risk factors, such as insulin-dependent diabetes mellitus, chronic obstructive pulmonary disease, body- massindex above $35 \mathrm{~kg} / \mathrm{m}^{2}$ (BMI > $\left.35 \mathrm{~kg} / \mathrm{m}^{2}\right)$, obesity in diabetic women. He also described intraoperative factors like prolonged bypass time, sternal devascularisation (by internal thoracic artery use) and harvesting technique (whether skeletonized or pedicled technique). Additionally, the authors pointed out that suboptimal primary sternal closure should be considered a significant intraoperative risk factor. This explains the necessity of a predictive scoring system that may help the surgeon in decision -making concerning the most appropriate sternal closure technique. This is called 'a tailored approach' in a publication of Nenna et al. [12]. They proposed a decisional algorithm based on clinical experience. The definition of high-risk patients comprises COPD, obesity, BITA use, diabetes, off-midline sternotomy. An algorithm for tailored sternal closure techniques is based on patients' risk factors and the surgeons' experience. The authors of this review are aware of the absence of consensus in the literature and the severe lack of RCT regarding the optimal sternal closure method.

Our scoring model is based on a multivariable logistic regression model, it predicts a sternal dehiscence more precisely than other scoring systems (AUC: 0.76). The risk factors are individually weighted and therefore, a more specific surgical technique can rationally be chosen and eventually higher costs are well justified.

\section{How to interpret the predictive scoring system (MUST- score)}

In the first step, the patients diagnoses are weighted with points in a scale from -1 to 5 (Table 4). Secondly, the total score represents the expected risk of sternal dehiscence within a range from 0.2 to $73.7 \%$ (Table 5).

The scaling is arbitrarily divided into a coloured traffic light scheme starting from

- green (score up to 4 points, representing an expected low risk of MUST below 1\%), to

- yellow (score up to 8 points, intermediate risk of MUST below 5\%), to

- red (score up to 11 points, high risk of MUST above 15\%) (Table 6).

The expected risk of malunion increases with the total score. As shown in Fig. 2, the graph follows an exponential curve with an increase behind a score of 10. We consider the risk as high and recommend specially reinforced techniques for the sternal closure as described in Table 6.

The surgeon may preoperatively calculate the patients risk group and plan the modification of the sternal closure technique. We consider this a well-

Table 6 Classification of risk groups and surgical technique modification

\begin{tabular}{|c|c|c|c|}
\hline Score & Risk & & Surgical technique \\
\hline 0 & $0.3 \%$ & low & Standard: \\
\hline 1 & $0.5 \%$ & & Single wires \\
\hline 2 & $0.7 \%$ & & \\
\hline 3 & $1.0 \%$ & $\leq 1.0 \%$ & \\
\hline 4 & $1.4 \%$ & Intermediate & Standard plus: \\
\hline 5 & $2.1 \%$ & & Special wiring techniques, \\
\hline 6 & $3.0 \%$ & & e.g. figure of eight, \\
\hline 7 & $4.3 \%$ & $<5 \%$ & intercostal, double wires \\
\hline 8 & $6.1 \%$ & high & Reinforced: \\
\hline 9 & $8.7 \%$ & & Wires plus bands or \\
\hline 10 & $12.2 \%$ & $<15 \%$ & rigid plates fixation ${ }^{a}$ \\
\hline 11 & $16.8 \%$ & Very high & Specially reinforced: \\
\hline 12 & $22.7 \%$ & & Rigid plates fixation (360-plates +bands ${ }^{b}$ ) \\
\hline 13 & $29.9 \%$ & $<30 \%$ & (minimum 3 plates, 5 bridges) \\
\hline 14 & $38.3 \%$ & Extremely high & Combination of plates and bands $\left(360^{\circ}\right)$ \\
\hline 15 & $47.5 \%$ & $<50 \%$ & other techniques: \\
\hline 16 & $56.9 \%$ & $>50 \%$ & Additional to Plates \\
\hline 17 & $65.8 \%$ & & Retention sutures \\
\hline$>18$ & $73.7 \%$ & & Vacuum-assisted wound closure \\
\hline
\end{tabular}

${ }^{\mathrm{a}}$ SternaLock ${ }^{\mathrm{TM}}$ Blue, ${ }^{\mathrm{b}}$ SternaLock ${ }^{\mathrm{TM}} 360$ 


\section{Expected risk of MUST (\%)}

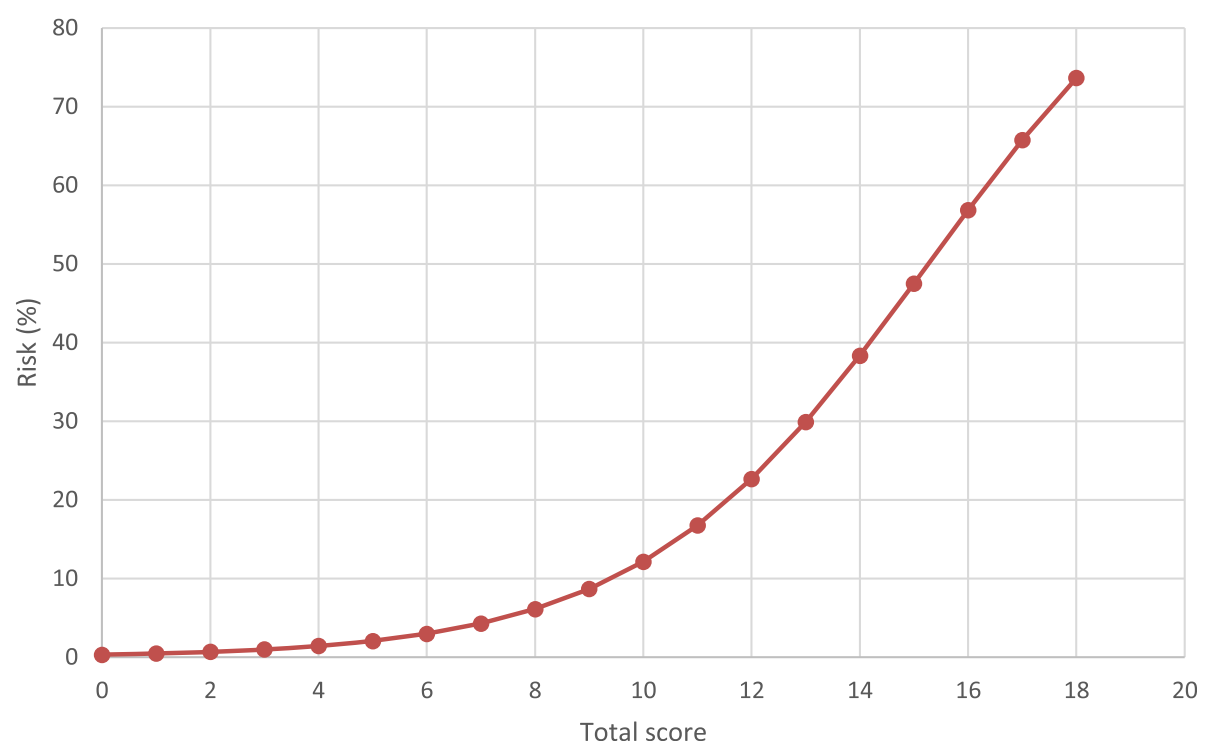

Fig. 2 The relationship between the total score and the expected risk of MUST. Legend: The expected risk of Malunion of the sternum (MUST) is shown. The graph shows a nearly exponential curve on the range of 0-12 points, afterwards, the graph follows nearly a straight line

tailored approach with an underlying rational score that fits the patients' needs as well as economical requirements.

\section{Study limitations}

Even the best scoring system does not relieve the surgeon from correct judgement and proper technical quality of the employed technique. Several clinical circumstances may limit the guidance of scores and the usage of extended techniques, e.g. diffuse bleeding with a certain probability of postoperative reexploration and hemodynamic instability.

From the statistician's point of view, the probabilities have to be interpreted with caution. The analysed complication (sternal dehiscence) is a rare event (2.5\%), thus the logistic regression model is lacking of some accuracy in the marginal zones (nearby 0 and 100\%). Exclusion criterion was the primary use of any other complex techniques for sternal osteosynthesis, so that some of the so-called high-risk patients potentially did not contribute to the complication group. As well as data of juvenile patients below an age of 18 years were not enrolled.

Experience and availability of special techniques cannot be taken for granted in each centre.

Further studies will have to validate the precision of the performance of this scoring system. In this future validation study, all data would be analysed that have been entered in the database after inauguration of the MUST-score in this department.

\section{Conclusion}

A weighted scoring system based on individual risk factors was specifically created to predict sternal dehiscence. This risk score accurately identifies high-risk patients who may benefit form tailored interventions aimed at the reduction of this severe complication of cardiac surgery.

High-scoring patients should receive more than standard closure techniques. Rigid plates fixation techniques even in combination with bands and external supportive techniques like retention sutures, support vests or vacuum-assisted wound closure may complete the surgeon's technical armament.

\section{Abbreviations}

AUC: Area under the curve; ROC Curve: Receiver Operating Characteristic curve; BITA: Bilateral internal thoracic arteries; CABG: Coronary artery bypass grafting; AIC: Akaike Information Criterion; MUST: Malunion of the sternum; BMI: Body Mass Index; NIDDM: Non- Insulin Dependent Diabetes mellitus; IDDM: Insulin dependent Diabetes mellitus; COPD: Chronic obstructive pulmonary disease

\section{Acknowledgements}

We thank Elisabeth Waldmann, PhD, (Institute of Medical Informatics, Biometry and Epidemiology, IMBE) for statistical advice.

\section{Authors' contributions}

EN: Investigation; Data collection; Writing- original draft. CG: Formal analysis; Data curation. JR: Data curation. MW: Conceptualization; Supervision; Writingreview. FH: Conceptualization; Project administration; Writing - review. All authors reviewed the manuscript. The author(s) read and approved the final manuscript

Funding

Open Access funding enabled and organized by Projekt DEAL. 


\section{Availability of data and materials}

Please contact corresponding author for data request.

\section{Declarations}

\section{Ethics approval and consent to participate}

This retrospective study complied with the Helsinki Declaration (2000) and approval to perform this analysis was given by the local Ethics Committee (EC, No.233_20 BC), based on retrospective data retrieval. For this reason, the EC waived the need for written patients' informed consent.

\section{Consent for publication}

Not applicable.

\section{Competing interests}

All authors declare no conflict of interest with respect to research, authorship and publication of the article.

\section{Author details}

'Department of Cardiac Surgery, University Hospital Erlangen, FriedrichAlexander University Erlangen- Nuremberg, Krankenhausstr. 12, D-91054 Erlangen, Germany. ${ }^{2}$ Institute of Medical Informatics, Biometry and Epidemiology (IMBE), Waldstr. 6, D-91054 Erlangen, Germany.

Received: 20 November 2020 Accepted: 30 May 2021

Published online: 14 June 2021

\section{References}

1. Milton H. Mediastinal surgery. Lancet. 1897;27:872-5.

2. Julian OC, Lopez-Belio M, Dye WS, Javid H, Grove WJ. The median sternal incision in intracardiac surgery with extracorporeal circulation; a general evaluation of its use in heart surgery. Surgery. 1957;42(4):753-61.

3. Fowler VG Jr, O'Brien SM, Muhlbaier LH, Corey GR, Ferguson TB, Peterson ED. Clinical predictors of major infections after cardiac surgery. Circulation. 2005:112:358-65.

4. Allen KB, Thourani VH, Naka Y, Grubb KJ, Grehan J, Patel N, et al. Randomized, multicenter trial comparing sternotomy closure with rigid plate fixation to wire cerclage. J Thorac Cardiovasc Surg. 2017;153(4):888-96. https://doi.org/10.1016/j.jtcvs.2016.10.093.

5. Hussey LC, Leeper B, Hynan LS. Development of the sternal wound infection prediction scale. Heart Lung. 1998;27(5):326-36. https://doi.org/1 0.1016/S0147-9563(98)90053-X.

6. Friedman ND, Bull AL, Russo PL, Leder K, Reid C, Billah B, et al. An alternative scoring system to predict risk for surgical site infection complicating coronary artery bypass graft surgery. Infect Control Hosp Epidemiol. 2007:28(10):1162-8. https://doi.org/10.1086/519534.

7. O'Connor GT, Plume SK, Olmstead EM, Coffin LH, Morton JR, Maloney CT, et al. Multivariate prediction of in-hospital mortality associated with coronary artery bypass graft surgery. Northern New England CardiovascularDisease study group. Circulation. 1992;85(6):2110-8. https:// doi.org/10.1161/01.CIR.85.6.2110.

8. Russo PL, Spelman DW. A new surgical-site infection risk index using risk factors identified by multivariate analysis for patients undergoing coronary artery bypass graft surgery. Infect Control Hosp Epidemiol. 2002;23(7):372-6. https://doi.org/10.1086/502068.

9. Ariyaratnam P, Bland M, Loubani M. Risk factors and mortality associated with deep sternal wound infections following coronary bypass surgery with or without concomitant procedures in a UK population: a basis for a new risk model? Interact Cardiovasc Thorac Surg. 2010;11(5):543-6. https://doi. org/10.1510/icvts.2010.237883.

10. Gatti G, Dell'Angela L, Barbati G, Benussi B, Forti G, Gabrielli M, et al. A predictive scoring system for deep sternal wound infection after bilateral internal thoracic artery grafting. Eur J Cardiothorac Surg. 2016;49(3):910-7. https://doi.org/10.1093/ejcts/ezv208.

11. Robicsek F, Fokin A, Cook J, Bhatia D. Sternal instability after midline sternotomy. Thorac Cardiovasc Surg. 2000;48(4):1-8. https://doi.org/10.1055/ s-2000-9945

12. Nenna A, Nappi F, Dougal J, Satriano U, Chello C, Mastroianni C, et al. Sternal wound closure in the current era: the need of a tailored approach. Gen Thorac Cardiovasc Surg. 2019:67(11):907-16. https://doi.org/10.1007/s11 748-019-01204-5.
13. Raman J, Lehmann S, Zehr K, De Guzman BJ, Aklog L, Garrett HE, et al. Sternal closure with rigid plate fixation versus wire closure: a randomized controlled multicenter trial. Ann Thorac Surg. 2012;94(6):1854-61. https:// doi.org/10.1016/j.athoracsur.2012.07.085.

14. Badellino M, Cavarocchi NC, Kolff J, Alpern JB, McClurken JB. Sternotomy closure with Parham bands. J Card Surg. 1988;3(3):235-6. https://doi.org/1 0.1111/j.1540-8191.1988.tb00242.x.

15. Core Team R. R: a language and environment for statistical computing. Vienna: R Foundation for statistical computing; 2020. URL https://www.Rproject.org/

16. Swets JA. Measuring the accuracy of diagnostic systems. Science. 1988; 240(4857):1285-93. https://doi.org/10.1126/science.3287615.

17. Losanoff JE, Richman BW, Jones JW. Disruption and infection of median sternotomy: a comprehensive review. Eur J Cardiothoracic Surg. 2002;21(5): 831-9. https://doi.org/10.1016/S1010-7940(02)00124-0.

\section{Publisher's Note}

Springer Nature remains neutral with regard to jurisdictional claims in published maps and institutional affiliations.

Ready to submit your research? Choose BMC and benefit from:

- fast, convenient online submission

- thorough peer review by experienced researchers in your field

- rapid publication on acceptance

- support for research data, including large and complex data types

- gold Open Access which fosters wider collaboration and increased citations

- maximum visibility for your research: over $100 \mathrm{M}$ website views per year

At BMC, research is always in progress.

Learn more biomedcentral.com/submissions 